\title{
Comparison of Impact Duration Between Experiment and Theory From Charpy Impact Test
}

\author{
N.B. Muhammad Said ${ }^{1, *}$, M.B. Ali ${ }^{1}$, K.A. Zakaria ${ }^{1}$, and M.A.M. Daud ${ }^{1}$ \\ ${ }^{1}$ Faculty of Mechanical Engineering, Universiti Teknikal Malaysia Melaka,Hang Tuah Jaya, 76100 \\ Durian Tunggal, Melaka, Malaysia.
}

\begin{abstract}
This study presents the comparison of impact duration between experiment and theory from impact signal through a Charpy test. Recently, the number of accidents on the highway has been increased and it depends on the impact duration of material that have the ability to provide adequate protection to passengers from harmful and improve occupant survivability during crash event. Charpy impact test was implemented on different material and thickness but at the same striker velocity. Impact signal is obtained through the strain gauge that has been installed to striker hammer and connected to frequency data acquisition system. Collected signal is then analysed to identify the time period during impact before fractured. Result from both experiment and theory shows an increment to the impact duration as thickness is increased. Charpy test shows that aluminium 6061T6 has a higher impact duration compared to carbon steel 1050.
\end{abstract}

\section{Introduction}

Impact on a body is occurring in a very short period of time with very large of force is imposed. According to Oztas [1], vehicle collision on highways can be classified as headon collision, front-to-back collision and eccentric collision and impact of that collision is strongly depends on the vehicle velocity, mass and material of the vehicle is made of. In vehicle collision, crashworthiness is an aspect that always becomes major attention in the automotive field because its ability to protect passengers from damage and improve occupant survivability during crash event. Previous study by Bhanage et al. [2] states that crashworthiness which includes the ability of the car to withstand minor accidents with little damage becomes a trend nowadays in the automotive industry. In engineering structures, strength and toughness often combined to indicate the amount of energy absorbed during the deformation and fracture.

In order to meet safety regulations, designers have to improve the structural design that can be applied in vehicle crashworthiness. However, the design for crashworthiness is a tough task in a design process often involves non-obvious decisions since the structure has to be strong enough in some zones to prevent passengers, yet sufficiently compliant in other

* Corresponding author: nurlaelamuhammadsaid@yahoo.com 
zones to absorb the crash energy [12]. Vehicle that is made from material with high impact duration is more safe since there are extended crush spaces for car protection which can reduce the damage either to car structure or occupant [7].

Some ways may apply for improving the safety condition in vehicles. Samer et. al [3] recommends that improvements on the security level of vehicle structure need to be achieved in order to enhanced the capabilities of energy absorption of vehicles. Good and high quality of energy absorber should be designed to dissipate the energy of impact irreversibly via plastic deformation of metallic structure. Most of the energy absorbers were developed using metallic thin-walled structure since they tend to deform plastically due to elastic-plastic behaviour [4].

Charpy impact test is widely applied for many years in the engineering field since it is easy to conduct, rapid test method, reliability and low cost. This test often implemented to study the failure behaviour besides of investigates the toughness of a material. Some aspects may affect the failure behaviour of Charpy impact test such as temperature, notch position, material properties and impact velocity.

Jang et al. [5] remarks that experimental and numerical studies were performed to study the effects of notch position on the failure behaviour and energy absorption when the Charpy V-notch impact test is made at temperature of $1^{\circ} \mathrm{C}$. Furthermore, Shende et al. [6] claims ductile-to-brittle transition curves may be obtained when the results of a number of tests presented in different temperatures is plotted. When the temperature is reduced through the range of transition, the fracture surface changes from one having a 'fibrous' or 'silky' appearance with much distortion at the sides, to one of completely crystalline appearance with negligible distortion.

Nowadays, vehicle collision has been increase per year was reported. Research on those phenomena is studied continuously in order to improve the performance of vehicles on the road. Great performances provide sufficient security or reduce the severity to occupants if a sudden collision happens. Thus, this study is conducted as a guideline for the next research to investigating the effect of parameters (materials, thickness, velocity) where it is one of the best method to be conducted in order to enhance the impact duration, so can reduce the risk during collision. The main purpose of this study is to compare the impact duration obtained from Charpy impact strain signal with theory. Since there are many factors that influence the impact duration, hence changes in the material and specimen thickness are two parameters that contribute in affecting the value of time required during impact before fracture occurs.

\section{Theory}

Based on Ali et al.[7], the total impact duration, $\mathrm{t}_{0}$ can be determined from the formula shown as follow.

where,

$$
t_{o}=2.94\left(\frac{5}{4 M n^{1} v^{1 / 2}}\right)^{2 / 5}
$$

$$
\begin{gathered}
\text { total mass, } M=\frac{1}{m_{1}}+\frac{1}{m_{2}} \\
m_{1}=\text { mass of impactor and } m_{2}=\text { mass of specimen } \\
v=\text { velocity during impact }
\end{gathered}
$$

and

$$
n^{1}=\frac{4 \sqrt{R_{1}}}{3 \pi\left(k_{1}+k_{2}\right)}
$$


where, $\quad k_{1}=\frac{1-v_{1}^{2}}{\pi E_{1}}$ and $\quad k_{2}=\frac{1-v_{2}^{2}}{\pi E_{2}}$

$v_{1}$ and $v_{2}=$ Poisson ratio of striker and specimen respectively

$E_{1}$ and $E_{2}=$ Young Modulus for striker and specimen respectively

$R_{1}=$ radius of a spherical impactor

Based on Rechnitzer et al. (Accident Research Centre) [8], impact is considered to be essentially plastic when two vehicles that approaching each other in opposite directions do not bounce apart and continue together with a combined mass in a straight line after impact occurs. Impact duration between cars and heavy vehicles can be performed by using equation 2 below.

$$
t=\frac{2 s}{V_{c}}
$$

where,

$t=$ impact duration

$s=$ car crush $(\mathrm{m})$ or overall deformation

$V c=$ closing velocity, $V_{1}+V_{2}$

$V_{1}=$ velocity of truck/heavy vehicle $(\mathrm{m} / \mathrm{s})$

$V_{2}=$ initial velocity of $\operatorname{car}(\mathrm{m} / \mathrm{s})$

\section{Methodology}

The figure 1 below shows the process involved in determining the impact duration. This study is started with material selection and preparation. Then, Charpy test was conducted to collect impact strain signal. Lastly, data on strain signal is analysed and compared to the theory.

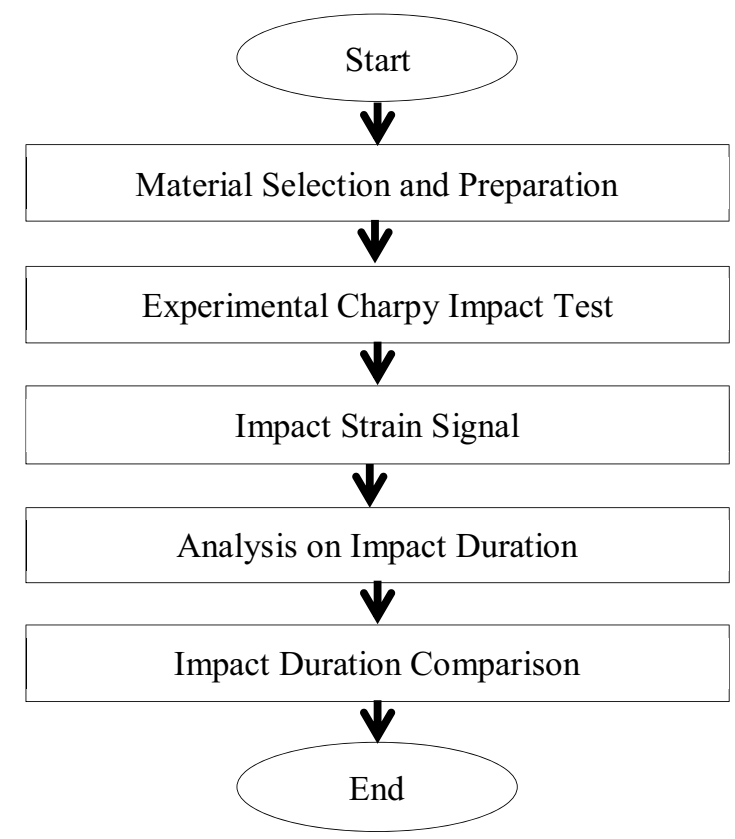

Fig. 1. Process in Impact Duration Determination. 


\subsection{Material selection}

Since the uses of aluminium and steel are widely used in engineering application, aluminium 6061-T6 and carbon steel 1050 were chosen for conducting the Charpy impact test. Both of these specimens were selected by considering their potential properties such as high strength, durable, good toughness, cost effective and corrosion resistance. The compositions of these materials are shown in Table 1 and Table 2. Impactor of machine is made from steel and assumed to be a rigid body since it is not deformable. Young's modulus, density and Poisson's ratio for that impactor are 7.86x103 kg/m3, $210 \mathrm{GPa}$ and 0.32 respectively. Table 3 represents the physical and mechanical properties for aluminium 6061-T6 and carbon steel 1050.

Table 1. Chemical composition of 6061 aluminium alloy [9]

\begin{tabular}{|c|c|c|c|c|c|c|c|c|c|}
\hline Element & $\mathbf{F e}$ & $\mathbf{C u}$ & $\mathbf{S i}$ & $\mathbf{Z n}$ & $\mathbf{M n}$ & $\mathbf{M g}$ & $\mathbf{C r}$ & $\mathbf{T i}$ & $\mathbf{A l}$ \\
\hline Mass [\%] & 0.16 & 0.19 & 0.71 & 0.04 & 0.02 & 0.94 & 0.08 & 0.03 & $\mathrm{Bal}$ \\
\hline
\end{tabular}

Table 2. Chemical composition of carbon steel 1050 [10]

\begin{tabular}{|c|c|c|c|c|}
\hline Element & C & Mn & Si & Fe \\
\hline Mass [\%] & 0.55 & 0.65 & 0.25 & 98.55 \\
\hline
\end{tabular}

Table 3. Properties of Aluminium 6061-T6 and Carbon steel 1050 [11]

\begin{tabular}{|c|c|c|}
\hline Properties & Aluminium 6061-T6 & $\begin{array}{c}\text { Carbon steel } \\
\mathbf{1 0 5 0}\end{array}$ \\
\hline Density $\left[\mathrm{kg} / \mathrm{m}^{3}\right]$ & 2700 & 7860 \\
\hline Young's Modulus $[\mathrm{GPa}]$ & 70 & 210 \\
\hline Poisson's Ratio & 0.35 & 0.32 \\
\hline Yield strength $[\mathrm{MPa}]$ & 292 & 660 \\
\hline Ultimate strength[MPa] & 328 & 675 \\
\hline
\end{tabular}

\subsection{Specimen design and preparation}

The design of specimen is prepared by referring to ASTM E23. Figure 2 below shows the standard geometry for V-notch Charpy impact specimen. All dimensions are measured in unit of millimetre $(\mathrm{mm})$. Since thickness is one of the manipulated variables, the other thickness of the specimen is $5 \mathrm{~mm}$ by reducing its width from $10 \mathrm{~mm}$. 


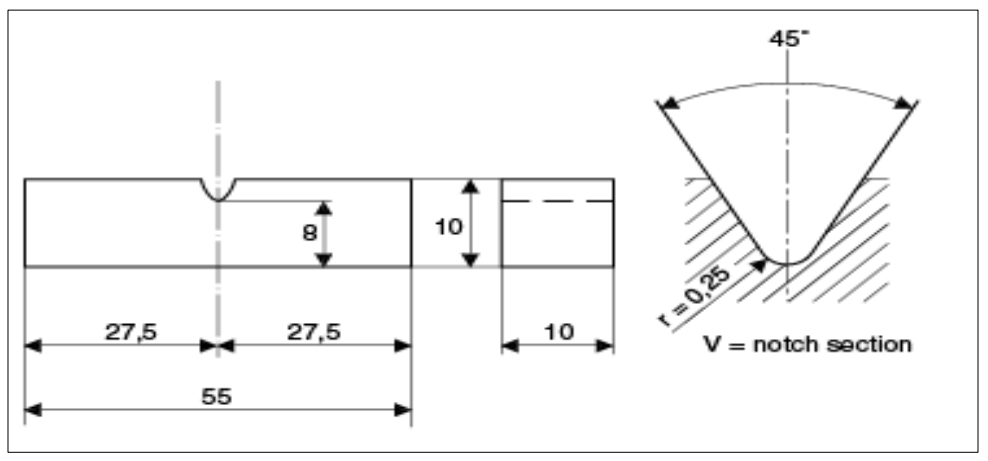

Fig. 2. Standard dimension of Charpy specimen.

\subsection{Equipment for testing}

Figure 3 shows equipment that was used in order to collect the information on the strain signal. Strain gauge was installed to the right and left striker surface that has radius of 2 $\mathrm{mm}$. In order to prevent the short circuit occurrence, direct contact between the chip surface of strain gauge and striker is avoided. In this study, frequency of $50 \mathrm{kHz}$ is selected, means that 50 data will be collected per second. After connection of all equipment is done, calibration on the Charpy machine is implemented by swing the pendulum without specimen on the test piece support. If the dial gauge on the Charpy machine shows zero reading, there is no problem for the machine to be used for data collection. The Charpy impact test is carried out under ambient temperature at a constant impactor velocity of 5.18 $\mathrm{m} / \mathrm{s}$.

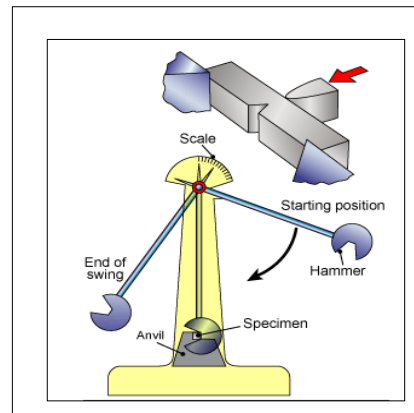

(a)

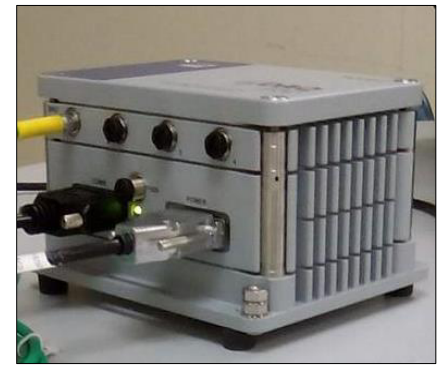

(b)

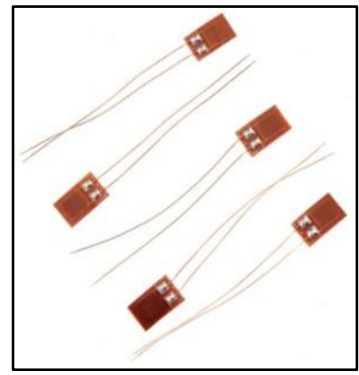

(c)

Fig. 3. Equipment for Charpy impact test in collecting strain signal: (a) Machine of Charpy impact (b) Data acquisition system (c) Strain gauge

\subsection{Impact duration analysis}

Collecting data from the experimental Charpy impact test is analysed by plotting a graph of strain against time. Then, average impact duration is calculated and compared to the formula that has been stated in Equations 1 and 2. 


\section{Result and discussion}

The signal obtained from a Charpy test is analysed by plotting a graph of strain versus time. The graphs are shown as below.

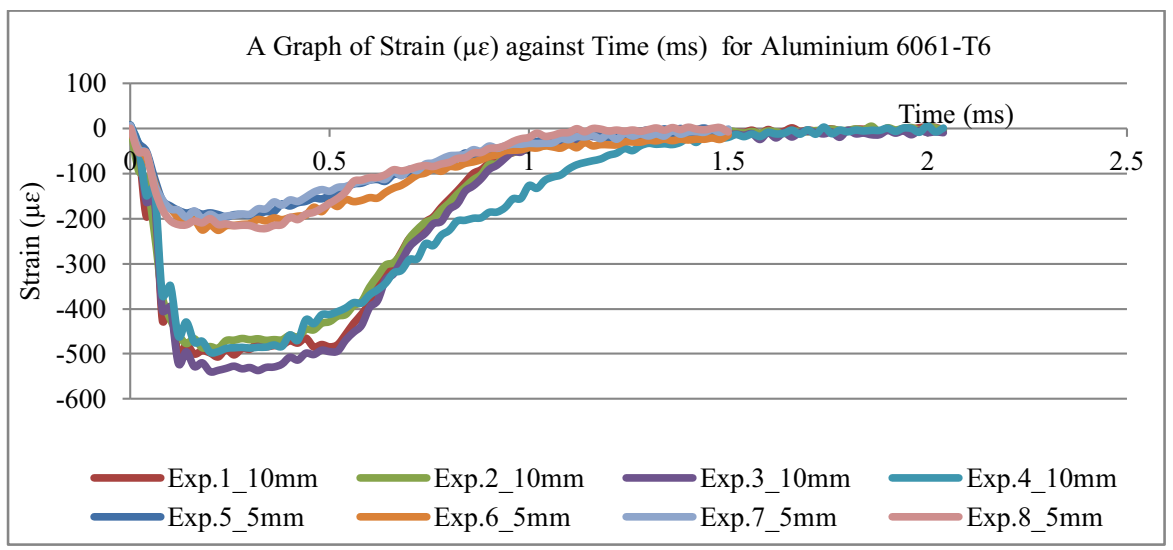

Fig. 4. Distribution of strain $(\mu \varepsilon)$ against time (ms) for Aluminium 6061-T6 at different thickness

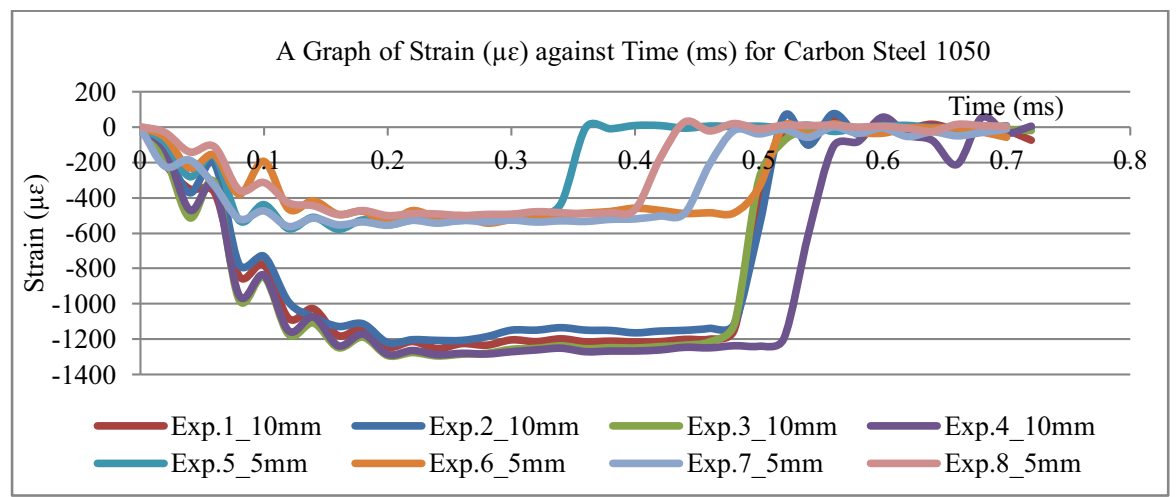

Fig. 5. Distribution of strain $(\mu \varepsilon)$ against time (ms) for Carbon Steel 1050 at different thickness

Based on the graphs above, for each material strain due to impact is directly proportional to the time taken during impact occurs. The range of impact duration for aluminium 6061 -T6 occurs between $1.1 \mathrm{~ms}$ to $1.5 \mathrm{~ms}$ and $0.38 \mathrm{~ms}$ to $0.60 \mathrm{~ms}$ for carbon steel 1050. For both materials, the highest impact duration was found in the thicker specimen. Charpy test results show an increment in impact duration when the thickness of the specimen was increased which is about $24 \%$ for aluminium and only $12 \%$ of carbon steel. Aluminium 6061-T6 has a higher average impact duration compared to Carbon steel 1050. It is because aluminium is more ductile than steel thus it has more elastic and plastic region in a stress - strain curve before fracture.

Impact duration from theory is calculated by using equation (1) and equation (2). By using equation 1, impact duration for aluminium has been increased about $32 \%$ and $28 \%$ of carbon steel when the thickness is doubled from $5 \mathrm{~mm}$. Identical pattern was found in impact duration when equation 2 is used. The impact duration has increased about $115 \%$ for 
aluminium while $118 \%$ of carbon steel if the thickness of specimen is increased. The comparison of impact duration between experiment and theory from previous study is summarized in Table 4 and Table 5 shows the percentage of increment in impact duration when the thickness of the specimen is raised. Results of theory show that carbon steel has a higher impact duration when compared to aluminium. It shows there is significant difference regarding the comparison between material changes in the scope of impact duration. Hence, more studies have to carry out to compare the time of impact between experiment and theory.

Meanwhile, changes in specimen thickness show a correlation if result from experiment and theory was compared. All cases indicate impact duration has been increased with thickness. This because thicker material requires more energy to fail and tends to absorb more energy once impact force is exerted and it will consequently affect the impact duration.

Table 4. Impact duration of experiment and theory

\begin{tabular}{|c|c|c|c|c|c|c|}
\hline \multirow{2}{*}{ Material } & \multicolumn{6}{|c|}{ Impact Duration [ms] } \\
\cline { 2 - 7 } & \multicolumn{2}{|c|}{ Experiment } & \multicolumn{2}{c|}{$\begin{array}{c}\text { Theory } \\
\text { [Equation 1] }\end{array}$} & \multicolumn{2}{c|}{$\begin{array}{c}\text { Theory } \\
\text { [Equation 2] }\end{array}$} \\
\cline { 2 - 7 } & $\mathbf{5 m m}$ & $\mathbf{1 0 m m}$ & $\mathbf{5 m m}$ & $\mathbf{1 0 m m}$ & $\mathbf{5 m m}$ & $\mathbf{1 0 m m}$ \\
\hline $\begin{array}{c}\text { Aluminium } \\
\text { 6061-T6 }\end{array}$ & 1.1500 & 1.4300 & 0.0496 & 0.0654 & 0.1004 & 0.2163 \\
\hline $\begin{array}{c}\text { Carbon Steel } \\
\text { 1050 }\end{array}$ & 0.4900 & 0.5500 & 0.0597 & 0.0764 & 0.2542 & 0.5541 \\
\hline
\end{tabular}

Table 5. Percentage of Increment on Impact Duration

\begin{tabular}{|c|c|c|}
\hline \multirow{2}{*}{ Cases } & $\begin{array}{c}\text { Increment of impact duration percentages from 5 } \\
\mathbf{m m} \text { to 10 } \mathbf{~ m m}[\mathbf{\%}]\end{array}$ \\
\cline { 2 - 3 } & $\begin{array}{c}\text { Aluminium } \\
\mathbf{6 0 6 1}-\mathbf{T 6}\end{array}$ & Carbon Steel 1050 \\
\hline Experiment (Charpy Test) & $24 \%$ & $12 \%$ \\
\hline Equation 1 & $32.5 \%$ & $28 \%$ \\
\hline Equation 2 & $115 \%$ & $118 \%$ \\
\hline
\end{tabular}

\section{Conclusion}

In both cases experiment and theory, the impact duration was increased as the specimen thickness is increased. This shows that the correlation between experiment and theory in term of impact duration is existed. It is because thicker structure requires more energy due to impact before fracture. In terms of material changes experimental result shows that aluminium 6061-T6 able to extend the time during impact occurs compared to carbon steel 1050. However, that result against with a theory where the impact duration of carbon steel is higher than aluminium. Hence, further studies on comparison of impact duration between experiment and theory need to reviewed continuously as a basis to derive a new formula or theory that link to the experiment in order as a guideline to reduce the risk during collision.

The authors would like to thank to the reviewer community who greatly help to produce this manuscript. Special thanks to financial support under grant of FRGS/2/2013/TK01/FKM/03/3/F00173. 


\section{References}

1. A.G. Oztas, Turkish J. Eng. Env. Sci., 23, 455 (1999)

2. A. Bhanage, N. Satonkar, P. Deshmukh, R. Sundge, International Journal of Engineering and Technology, 6, 2129 (2014)

3. F. Samer, A. Abdullah, J.O. Sameer, International Journal of Advanced Engineering and Nano Technology, 2, 1 (2015)

4. L.K.O.K. Hao, A. Radzi, A. Ghani, P. Edi, K. Yusuf, WSEAS Transactions on Applied and Theoretical Mechanics, 4, 95 (2009)

5. Y.C. Jang, J.K. Hong, J.H. Park, D.W. Kim, Y.Lee, J. Mater. Process. Tech., 201, 419 (2008)

6. C.J. Shende, A.R. Sahu, A.V. Deshmukh, Int. J. Mech. Eng. \& Rob. Res., 4, 350 (2015)

7. M.B. Ali, S. Abdullah, M.Z. Nuawi, A.K. Ariffin, Indian J. Eng. Mater. S., 20, 504 (2013)

8. G. Rechnitzer, C. Powell, K. Seyer, Performance Criteria, Design and Crash Tests of Effective Rear Underride Barriers For Heavy Vehicles, 218 (SAE International, 2001)

9. S.H. Lee, Y. Saito, T. Sakai, H. Utsunomiya, Mat. Sci. Eng. A-Struct., 325, 228 (2002)

10. S.K. Jaiswal, T. Sharma, M. Rajesh, V. Kumar, Study of the Hardness and the Microstructure of AISI 1050 Medium Carbon Steel after Heat Treatment Processes (ELK Asia Pacific Journals, Delhi,-Special Issue)

11. M.B. Ali, S. Abdullah, M.Z. Nuawi, A.K. Ariffin, Appl. Mech. Mater., 165, 182 (2012)

12. K. Hamza, K. Saitou, Design for Crashworthiness of Vehicle Structures via Equivalent Mechanism Approximations and Crush Mode Matching (ASME, Anaheim, 2004) 